\title{
Bone and Parathyroid Inhibitory Effects of S-2(3-Aminopropylamino)ethylphosphorothioic Acid Studies in Experimental Animals and Cultured Bone Cells
}

\author{
M. F. Attie, M. D. Fallon, B. Spar, J. S. Wolf, E. Slatopolsky, and S. Goldfarb \\ Endocrine and Renal-Electrolyte Sections, Department of Medicine, and the Department of Pathology, University of \\ Pennsylvania School of Medicine, Philadelphia, Pennsylvania 19104; and Renal Division, Department of Medicine, \\ Washington University School of Medicine, St. Louis, Missouri 63110
}

\begin{abstract}
S-2-(3-aminopropylamino)ethylphosphorothioic acid (WR 2721) is a radio- and chemoprotective agent which produces hypocalcemia in humans. Intravenous injection of $30 \mathrm{mg} / \mathrm{kg} \mathrm{WR}$ 2721 in rats and $15 \mathrm{mg} / \mathrm{kg}$ in dogs lowers serum calcium by 19 and $25 \%$, respectively. Hypocalcemia in dogs is associated with a fall in serum immunoreactive parathyroid hormone (PTH), which suggests that the mechanism of its hypocalcemic effect is acute hypoparathyroidism. Despite this effect on PTH, in eight chronically parathyroidectomized rats on a low phosphate diet, WR 2721 reduced serum calcium from $9.4 \pm 0.6$ to $7.7 \pm 0.5 \mathrm{mg} / \mathrm{dl}(P<0.01)$ at $3 \mathrm{~h}$. Furthermore, in dogs rendered hypercalcemic by continuous infusion of PTH, WR 2721 reduced serum calcium from $11.0 \pm 0.5$ to $10.6 \pm 0.5 \mathrm{mg} / \mathrm{dl}$ $(\boldsymbol{P}<\mathbf{0 . 0 1})$.

To determine whether WR 2721 causes hypocalcemia by enhancing the exit of calcium from the circulation or inhibiting its entry, the drug was infused $3 \mathrm{~h}$ after administration of ${ }^{45} \mathrm{Ca}$ to rats. WR 2721 did not significantly increase the rate of disappearance of ${ }^{45} \mathrm{Ca}$ from the circulation even though serum calcium fell by $19 \%$. However, serum ${ }^{45} \mathrm{Ca}$ specific activity was higher at $1.5 \mathrm{~h}(P<0.01)$ and $3 \mathrm{~h}(P<0.05)$ in rats given WR 2721 than in rats given vehicle alone, which suggests that WR 2721 blocks the entry of nonradioactive calcium into the circulation, presumably from bone.

In incubations with fetal rat long bone labeled in utero with ${ }^{45} \mathrm{Ca}, 10^{-3}$ M WR 2721 inhibited PTH-stimulated, but not base-line release of ${ }^{45} \mathrm{Ca}$. Bone resorption by primary culture of chick osteoclasts was inhibited by WR 2721 at concentrations as low as $10^{-4} \mathrm{M}$ in the absence of hormonal stimulation.

These studies suggest that WR 2721 lowers serum calcium predominantly by blocking calcium release from bone. This acute hypocalcemic effect is at least in part independent of its effect on the parathyroid glands, and is most likely a direct effect of the agent on bone resorption.
\end{abstract}

This paper was presented in part at the Annual Meeting of the American Society of Nephrology, Washington, DC, 1983, and at the Annual Meeting of the American Federation of Clinical Research, 1984, and was published in abstract form in Clin. Res. 32:412A.

Address reprint requests to Dr. Attie, University of Pennsylvania.

Received for publication 18 April 1984 and in revised form 9 November 1984.

J. Clin. Invest.

(c) The American Society for Clinical Investigation, Inc.

$0021-9738 / 85 / 04 / 1191 / 07 \quad \$ 1.00$

Volume 75, April 1985, 1191-1197

\section{Introduction}

We recently reported that $S$-2(3-aminopropylamino)ethylphosphorothioic acid ${ }^{1}$ (WR 2721) $)^{2}$ produces acute transient hypocalcemia in humans (1). WR 2721 is an organic thiophosphate and sulfhydryl donor that protects cells against the lethal effects of ionizing radiation and alkylating agent chemotherapy (2). In the murine model, it protects skin and bone marrow from radiation but does not increase the radiation resistance of mammary tumors $(3,4)$. During clinical trials to determine the toxicity and effectiveness of this compound as a radio- and chemoprotector in humans receiving antitumor therapy, hypocalcemia was serendipitously discovered. In normocalcemic patients given a single intravenous infusion of WR $2721\left(740 \mathrm{mg} / \mathrm{M}^{2}\right)$, serum calcium levels decreased $23 \%$ in $2 \mathrm{~h}$ and remained depressed for at least $24 \mathrm{~h}$. WR 2721induced hypocalcemia was also accompanied by a fall in serum immunoreactive parathyroid hormone (PTH) concentration and urinary cyclic AMP excretion (1). These clinical observations, as well as the in vitro demonstration that WR 2721 blocked the release of PTH from isolated bovine parathyroid cells (1), suggested that acute inhibition of PTH secretion mediates the hypocalcemia induced by WR 2721 . The rapid sequence of events, however, does not support this hypothesis. In contrast to WR 2721 administration, serum calcium levels decrease much less rapidly following surgical removal of the parathyroid glands where there is usually no detectable change in serum calcium levels for at least 2-4 h (5). Thus, although WR 2721 acutely inhibits PTH secretion, the rapidity of the fall in serum calcium levels after WR 2721 suggested that inhibition of PTH secretion was not the sole mechanism.

The present study was undertaken to evaluate further mechanisms by which WR 2721 acutely produces hypocalcemia. Using PTH-infused dogs and parathyroidectomized (PTX) rats, we show that WR 2721 produces hypocalcemia by a mechanism independent of its inhibition of PTH secretion. By analyzing the kinetics of ${ }^{45} \mathrm{Ca}$ in rats we find evidence that WR 2721 lowers serum calcium by inhibiting the flux of calcium into the circulation, apparently by reducing bone resorption. Further, using fetal rat bone organ cultures and primary cultures of avian osteoclasts, we establish that WR 2721 directly inhibits bone resorption. These additional studies suggest that the acute hypocalcemic action of WR 2721 is

1. $\mathrm{H}_{2} \mathrm{NCH}_{2} \mathrm{CH}_{2} \mathrm{NNCH}_{2} \mathrm{CH}_{2} \mathrm{SPO}_{3} \mathrm{H}_{2} \cdot \mathrm{H}_{2} \mathrm{O}$.

2. Abbreviations used in this paper: $\mathrm{PTH}$, parathyroid hormone; $\mathrm{PTX}$, parathyroidectomy or parathyroidectomized; WR 2721, S-2(3-aminopropylamino)ethylphosphorothioic acid. 
mediated by a dual mechanism, resulting in the direct and indirect inhibition of osteoclastic bone resorption.

\section{Methods}

\section{In vivo experiments}

Studies in rats. Male Sprague-Dawley rats weighing 120-200 g were fed a standard rat diet containing $1.0 \%$ phosphorus and $1.0 \%$ calcium or, when specified, a low phosphorus diet containing $0.02 \%$ phosphorus and $0.8 \%$ calcium (ICN Nutritional Biochemicals, Cleveland, $\mathrm{OH}$ ) Food, but not water, was withheld for $16 \mathrm{~h}$ before each experiment. WR 2721 or vehicle was administered by rapid infusion $(<15 s)$ into a tail vein or intraperitoneally. Blood samples were obtained by cardiac puncture with a 26-gauge needle during light ether anesthesia. WR 2721 was dissolved no more than $15 \mathrm{~min}$ before administration in a solution containing $40 \mathrm{mM}$ sodium chloride and $40 \mathrm{mM}$ sodium bicarbonate (final pH 7.5), to give a final concentration of $30 \mathrm{mg} / \mathrm{ml}$.

Parathyroidectomy was performed under sodium pentobarbital anesthesia. Parathyroid glands were visualized under a dissecting microscope and surgically removed, leaving the thyroid glands intact. Sham-operated rats underwent the same procedure including exposure of the parathyroid glands, but the glands were not removed. Rats were considered to have adequate PTX if the serum calcium was $<8.0 \mathrm{mg} /$ $\mathrm{dl}$ at 3 and $7 \mathrm{~d}$ after PTX when fed the standard rat diet.

In experiments examining the kinetics of acutely injected radiocalcium, $100 \mu \mathrm{Ci} / \mathrm{kg}$ body weight of ${ }^{45} \mathrm{CaCl}_{2}$ (New England Nuclear, Boston, $\mathrm{MA} ; 27 \mathrm{Ci} / \mathrm{g})$ was dissolved in normal saline $(0.5 \mathrm{ml} / \mathrm{kg})$ and injected into a tail vein $2 \mathrm{~h}$ before injection of WR 2721. In experiments examining the kinetics of radiocalcium release from prelabeled bone pools, ${ }^{45} \mathrm{CaCl}_{2}(500 \mu \mathrm{Ci} / \mathrm{kg})$ was injected subcutaneously $17 \mathrm{~d}$ before injection of WR 2721 . Blood samples $(0.25 \mathrm{ml})$ were taken at various time intervals and ${ }^{45} \mathrm{Ca}$ activity in 0.025 - $\mathrm{ml}$ aliquots of serum was measured in triplicate by liquid scintillation spectrometry in BudgetSolve (Research Products International Corporation, Prospect, IL). Total serum calcium was measured by atomic absorption spectrophotometry. ${ }^{3}$

Studies in dogs. Female mongrel dogs weighing $15-20 \mathrm{~kg}$ were fasted for $16 \mathrm{~h}$ before experiments. After anesthesia was induced with intravenous pentobarbital, catheters were placed in the femoral vein and artery and in the urinary bladder. A normal saline infusion of 0.5 $\mathrm{cc} / \mathrm{min}$ was administered throughout the experiment. Blood losses were replaced with normal saline. Arterial blood pressure was measured via the femoral artery catheter with a Statham pressure transducer (GouldStatham Inc., Oxnard, CA), and body temperature monitored with a rectal probe (Yellow Springs Instruments, Yellow Springs, $\mathrm{OH}$ ). Arteria blood samples were withdrawn under oil for measurement of calcium and phosphate. In some experiments, female mongrel dogs (15-20 kg, $n=4$ ) underwent thyroparathyroidectomy $1.5 \mathrm{~h}$ before clearance experiments as previously described (5).

WR 2721 was dissolved in buffered lactated Ringer's (pH 7.2-7.3). A $50 \mathrm{mg} / \mathrm{ml}$ solution was infused at a dose of $15 \mathrm{mg} / \mathrm{kg}$ over a period of $20 \mathrm{~min}$ via the femoral venous catheter. Care was taken to flush the intravenous line with $20 \mathrm{ml}$ buffered lactated Ringer's before and after the WR 2721 infusion.

PTH infusions in dogs. A synthetic amino terminal (1-34) component of bovine PTH was infused as a $5 \mathrm{U} / \mathrm{kg}$ intravenous bolus followed by $4 \mathrm{U} / \mathrm{kg}$ per $\mathrm{h}$ infusion over a period of $6 \mathrm{~h}$. PTH was infused into a vein distant from any WR 2721 infusion. The dose for a single experiment was dissolved in $30 \mathrm{ml}$ of vehicle $(29 \mathrm{ml}$ saline

3. Addition of $1 \mathrm{mM}$ WR 2721 to calcium-referenced sera resulted in no interference with atomic spectrometric analysis of calcium level or with radioimmunoassay of PTH. Levels of WR 2721 in plasma after intravenous infusion in dogs have not been measured, however; assuming distribution initially only in plasma, the peak plasma levels would be $1.2 \mathrm{mM}$; assuming distribution in extracellular fluid, the maximal level would be $0.3 \mathrm{mM}$. and $1 \mathrm{ml}$ serum from the dog receiving the infusion) and kept on ice before use. Serum calcium was measured titrametrically (Calcette, Precision Systems, Sudberry, MA). Ionized calcium was measured with an SS-20 ion specific electrode (Orion Research, Cambridge, MA). Ultrafilterable calcium and phosphate were measured by standard techniques (5). PTH was measured by radioimmunoassay using a chicken anti-bovine PTH antisera and ${ }^{125}$ I bovine PTH (6). The assay is predominantly sensitive to $\mathrm{C}$-terminal, mid-region, and intact bovine hormone. The upper limit of normal in dogs is $40 \mu \mathrm{leq} / \mathrm{ml}$.

\section{In vitro experiments}

Bone resorption in organ culture. Bone resorption by cells in organ culture was performed using standard techniques (7). Briefly, the radii and ulnae of day 21 fetal rats, previously radio-labeled in utero by maternal injection of $100 \mu \mathrm{Ci}^{45} \mathrm{CaCl}_{2}$, were dissected free and cultured separately in $0.5 \mathrm{ml}$ BGJ media (Gibco Laboratories, Grand Island, NY) containing $50 \mu \mathrm{g}$ gentamicin and $1 \mathrm{mg} / \mathrm{ml}$ albumin. After a 4$18 \mathrm{~h}$ preculture period, bones were transferred to fresh media containing 0 or $10^{-3}-10^{-6} \mathrm{M}$ WR 2721 , and cultured for $5 \mathrm{~d}$. Resorption is expressed as percent ${ }^{45} \mathrm{Ca}$ released, and was determined by measuring both ${ }^{45} \mathrm{Ca}$ activity in the culture media and label remaining in the bone rudiment. To some bone-containing wells, 200 or $1,000 \mathrm{ng} / \mathrm{ml}$ of (1-34) bovine PTH was added at the beginning of the culture period. Mean values and SEM are calculated from replicates of six for each variable.

Bone resorption by isolated osteoclasts. Osteoclasts were isolated from day 21 hatchling chicks by trypsin digestion of soft tissue marrowfree split segments of tibial bones, using the technique of Osdoby (8). Histochemical staining and electron microscopy show that $80-90 \%$ pure populations of osteoclasts were obtained (8). As described in preliminary reports, isolated avian osteoclasts can mediate cell contactdependent bone resorption (9). To determine bone resorptive activity in vitro, one million osteoclasts were suspended with $0.22 \mathrm{mg}$ of ${ }^{45} \mathrm{Ca}$ labeled, devitalized, $75-300-\mu \mathrm{m}$ diameter bone particles $(10)$ per milliliter of minimum essential medium supplemented with $10 \%$ fetal calf serum and $50 \mu \mathrm{g} / \mathrm{ml}$ gentamicin. The cell-bone suspension $(0.2 \mathrm{ml})$ was delivered to the bottom of sterile microtiter wells. The following day, nonadherent cells and bone were removed by aspiration and fresh medium containing $0-10^{-3} \mathrm{M}$ WR 2721 was added. Cultures were incubated for $1-7 \mathrm{~d}$ in humidified $5 \% \mathrm{CO}_{2}$ in air at $37^{\circ} \mathrm{C}$. Bone resorption is expressed as percent ${ }^{45} \mathrm{Ca}$ release determined by measuring the fraction of radioisotope present in the media and that remaining in the bone (10). Net (cell specific) percent ${ }^{45} \mathrm{Ca}$ release is determined by correcting the total percent ${ }^{45} \mathrm{Ca}$ release for nonspecific release of label due to simple physicochemical exchange.

Morphologic studies. The effect of $10^{-3}$ M WR 2721 on the ability of osteoclasts to exclude $0.1 \%$ solution of Trypan Blue was examined on freshly isolated cells, and on cells at day 4 of culture. In some experiments, bone rudiments or bone containing osteoclast cell cultures were fixed in $2 \%$ glutaraldehyde, decalcified in $7 \%$ EDTA, and processed in a routine fashion for transmission electron microscopy.

Materials. WR 2721 was obtained from the Drug Synthesis and Chemistry Branch, National Cancer Institute, and was kindly provided by Dr. Morton Kligerman. Synthetic bovine amino terminal (1-34) PTH and purified intact bovine (1-84) PTH were obtained from Beckman Instruments Inc., Fullerton, CA.

Statistics. Statistical analyses were done using $t$ test for paired or nonpaired data where appropriate. Data are shown as mean \pm SEM.

\section{Results}

In vivo effects of WR 2721 on serum calcium, phosphorus, and $P T H$. Administration of WR 2721 consistently produced a dose-dependent reduction of serum calcium concentration in rats (Fig. 1). The hypocalcemic effect of WR 2721 appeared to be near maximal at doses of $60-120 \mathrm{mg} / \mathrm{kg}$. No toxic effects of the agent were seen at any of the doses used. These doses 


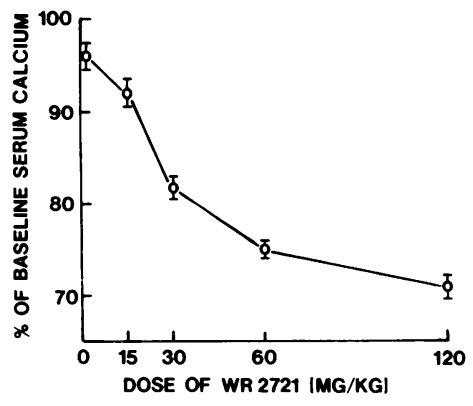

Figure 1. Dose-response curve for the action of WR 2721 on serum calcium in intact rats. Each point represents the mean \pm SEM of 5-6 rats treated with the indicated dose by intraperitoneal injection. The serum calcium is expressed as the percentage of the serum calcium before drug administration (11.2 \pm 0.4 in WR 2721 -infused and $10.9 \pm 0.4$ in vehicle-infused rats). Serum calcium was measured $4 \mathrm{~h}$ after WR 2721 administration.

are probably well below the $\mathrm{LD}_{50}$ which, in mice, is $850-1,050$ $\mathrm{mg} / \mathrm{kg}$ (11). All subsequent experiments in rats were performed using a $30-\mathrm{mg} / \mathrm{kg}$ dose to minimize the phosphate load since, if WR 2721 is hydrolyzed during metabolism, equimolar amounts of phosphate would be released. In normal rats, 30 $\mathrm{mg} / \mathrm{kg}$ WR 2721 consistently lowered the serum calcium by $16-22 \%$; a fall in serum calcium was seen as early as $30 \mathrm{~min}$ after drug administration (the earliest time point tested), persisted for at least $7 \mathrm{~h}$, and returned to preinjection levels by $24 \mathrm{~h}$.

It is likely, though not conclusively demonstrated, that WR 2721 is dephosphorylated during metabolism, perhaps by the enzyme alkaline phosphatase for which it is a substrate $(12,13)$. At the time WR 2721 exerted its maximum hypocalcemic effect (1-2 h), serum levels of phosphorus were unchanged. At $4 \mathrm{~h}$ after infusion of WR 2721 there was a slight increase in serum phosphorus $(23 \pm 6 \%)$, however, this was not significantly greater $(P<0.10)$ than in animals given vehicle alone $(9 \pm 4 \%)$. Moreover, infusion of phosphate as sodium phosphate in amounts equimolar to the quantity in the 30- or $60-\mathrm{mg} / \mathrm{kg}$ dose had no effect on the serum calcium (data not shown). These data preclude a rise in extracellular phosphate due to WR 2721 metabolism as a cause of acute hypocalcemia. Though unlikely, we can not exclude the possibility that these effects result from changes in intracellular phosphate levels.

In dogs, WR 2721 produced a similar degree of hypocalcemia. $4 \mathrm{~h}$ after infusion of $15 \mathrm{mg} / \mathrm{kg}$ WR 2721 in four dogs, there was a significant fall in total serum calcium $(10.1 \pm 0.14$ $8.24 \pm 0.22 \mathrm{mg} / \mathrm{dl}, P<0.001)$ that was not seen in animals infused with vehicle alone $(9.60 \pm 0.34-9.16 \pm 0.46 \mathrm{mg} / \mathrm{dl}$, $P>0.10)$. As in our previous finding in humans (1), this fall in total serum calcium was accompanied by a similar reduction in both ultrafilterable $(6.00 \pm 0.06-4.94 \pm 0.10 \mathrm{mg} / \mathrm{dl})$ and ionized calcium $(4.64 \pm 0.18-3.96 \pm 0.08 \mathrm{mg} / \mathrm{dl})$ and by a significant fall in serum PTH immunoreactivity $(20.5 \pm 8.4-5.8 \pm 3.3 \mu \mathrm{l} \mathrm{Eq} /$ $\mathrm{ml}, P<0.01)$. Acute hypocalcemia of this magnitude produced by EDTA or phosphate increases PTH (14). Since the patients treated with WR 2721 had various malignancies and were being treated with chemotherapeutic agents, the results in normal dogs indicate that the PTH-inhibitory effect in such patients was not dependent on some aspect of their underlying disease or interraction with other drugs.

In thyroparathyroidectomized dogs $(n=4)$, WR 2721 infusion did not increase urinary calcium excretion (percentage fractional excretion of filtered calcium: basal $0.48 \pm 0.26,3 \mathrm{~h}$ after WR 2721 infusion $0.34 \pm 0.11$ ) while serum calcium fell from $10.0 \pm 0.7$ to $7.5 \pm 0.1 \mathrm{mg} / \mathrm{dl}$ over the same time interval. Thus, in the absence of parathyroid glands, WR 2721 infusion is not associated with an increase in urinary calcium excretion.

Effect of WR 2721 infusion on serum calcium in PTX rats. To determine whether the hypocalcemic effect of WR 2721 occurs independent of the inhibitory effect on the parathyroid gland, we studied its effects in chronically parathyroidectomized rats. Serum calcium $3 \mathrm{~d}$ after surgery while on a standard (1\%) phosphate diet was $6.0 \pm 0.4 \mathrm{mg} / \mathrm{dl}$ in PTX rats and $10.2 \pm 0.2$ $\mathrm{mg} / 100 \mathrm{ml}$ in sham-operated animals $(P<0.0001)$ (Fig. 2). PTX and sham-operated rats were then maintained on a low (0.02\%) phosphorus diet to raise serum calcium in the PTX rats to the levels observed in the sham-operated animals. After $7 \mathrm{~d}$ on a phosphorus-deficient diet, mean serum calcium was 9.6 and $10.2 \mathrm{mg} / 100 \mathrm{ml}$ in PTX and sham-operated rats $(P>0.05)$, respectively (Fig. 2$)$. Thus, at the time of the WR 2721 infusion, the serum calcium levels of the two groups were similar. As shown in Fig. 2, WR 2721 infusion produced a nearly identical fall in serum calcium in both groups (20.2 $\pm 2 \%$ in PTX and $20.8 \pm 1 \%$ in sham-operated rats). To confirm that the hypoparathyroid status of the rats had not changed, the rats were once more fed the standard $(1.0 \%$ phosphorus) diet. Serum calcium concentrations were again lower in all PTX rats (Fig. 2).

Effects of WR 2721 on PTH-infused dogs. PTH infusions in seven dogs raised total serum calcium from $10.1 \pm 0.3$ to $11.2 \pm 0.4 \mathrm{mg} / \mathrm{dl}$ over $6 \mathrm{~h}(P<0.05)$. When the same dogs were treated with PTH plus WR 2721, serum calcium rose from $10.2 \pm 0.3$ to $11.0 \pm 0.5 \mathrm{mg} / \mathrm{dl}$ with $2 \mathrm{~h}$ of PTH infusion $(P<0.02)$, fell to $10.6 \pm 0.51 \mathrm{~h}$ after WR $2721(P<0.001$ when compared with a similar time point during PTH infusion without WR 2721), and then slowly rose (Fig. 3). The serum

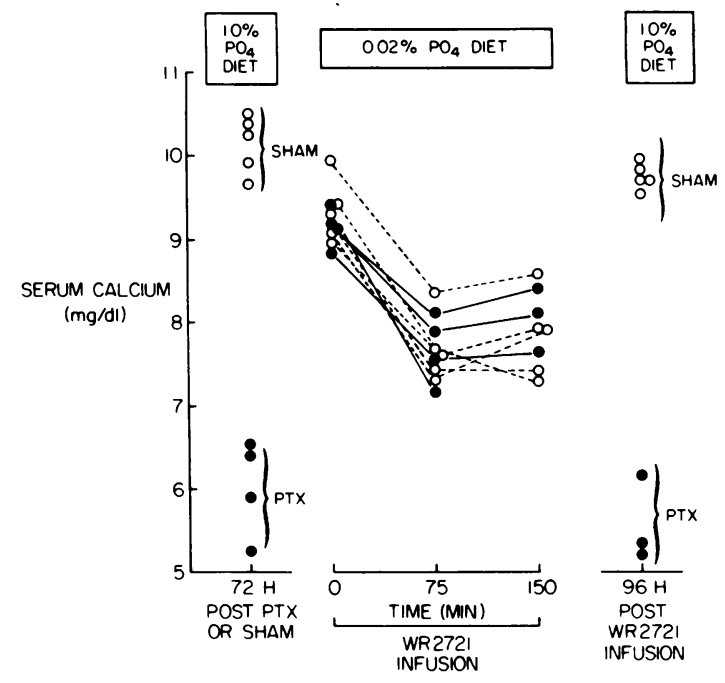

Figure 2. Effect of WR 2721 in PTX and sham-operated rats. Serum calcium concentration was measured $72 \mathrm{~h}$ after parathyroidectomy or sham operation while on a standard diet containing $1.0 \%$ phosphorus (left panel). Dietary phosphorus was then decreased to $0.02 \%$. After 7 $\mathrm{d}$ on this diet, WR $2721(30 \mathrm{mg} / \mathrm{kg})$ was infused via tail vein and serum calcium concentration measured (middle panel) immediately before drug administration ( 0 time) and then 75 and 150 min later. After the infusion the diet was again changed to the standard (1\%) phosphorus diet, and $96 \mathrm{~h}$ later serum calcium concentration was measured (right panel). One rat died during the infusion as a result of inadvertent ether overdosage. 


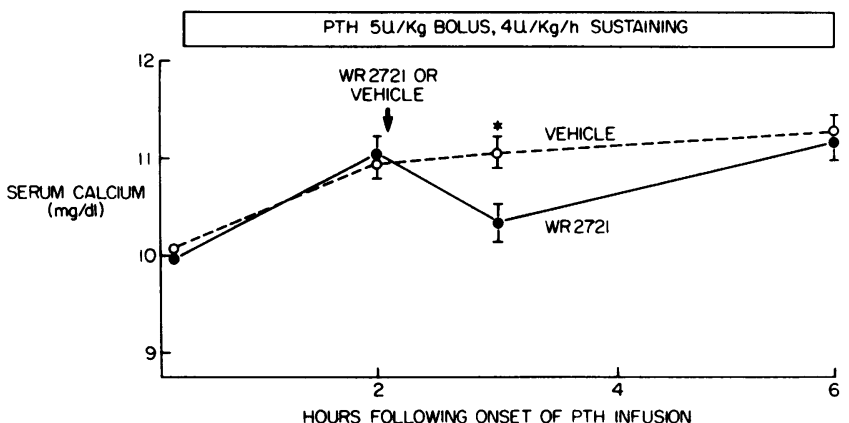

Figure 3. Effect of WR 2721 on serum calcium in dogs receiving exogenous PTH infusions. WR $2721(15 \mathrm{mg} / \mathrm{kg})$ or vehicle was given $2 \mathrm{~h}$ after a PTH infusion was started. The serum calcium was significantly lower in the WR 2721 -infused dogs at $3 \mathrm{~h}(P<0.01)$ Points represent mean values \pm SEM for six dogs in each group.

Ca was significantly lower in WR 2721-treated animals for up to $2 \mathrm{~h}$. There was no difference in serum phosphorus levels between the two groups measured at $2 \mathrm{~h}$ after infusion $(5.49 \pm 0.31 \mathrm{mg} / \mathrm{dl}$ in WR 2721 -infused and $5.69 \pm 0.27 \mathrm{mg} / \mathrm{dl}$ in vehicle-infused dogs). There was also no difference in the phosphaturic effect of PTH between vehicle and WR 2721 infusions $\left(\mathrm{FE} \mathrm{PO}_{4} 22 \pm 8 \%\right.$ basal, $34 \pm 9 \%$ post-PTH + vehicle; $11 \pm 6 \%$ basal, $24 \pm 9 \%$ post-PTH + WR 2721 ).

Effect of WR 2721 on radiocalcium kinetics in rats. Kinetic analysis of ${ }^{45} \mathrm{Ca}$ was used to determine whether WR 2721 produces hypocalcemia by accelerating the exit of calcium from the circulation, or by inhibiting its entry. WR 2721 or vehicle was given $2 \mathrm{~h}$ after an acute intravenous infusion of ${ }^{45} \mathrm{Ca}$. As shown in Fig. 4, WR 2721 acutely lowered serum

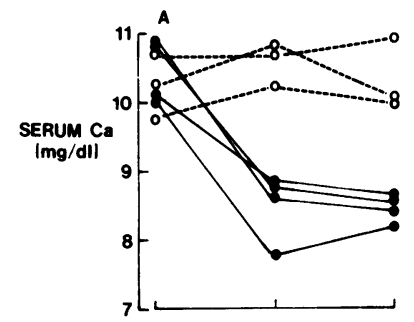

Figure 4. Effect of WR 2721 on total serum calcium serum ${ }^{45} \mathrm{Ca}$ activity, and serum ${ }^{45} \mathrm{Ca}$ specific activity. WR $2721(30 \mathrm{mg} / \mathrm{kg})$ or vehicle was given $2 \mathrm{~h}$ after infusion of ${ }^{45} \mathrm{CaCl}_{2}$ as described in Methods. $(A)$ Total serum calcium concentration.
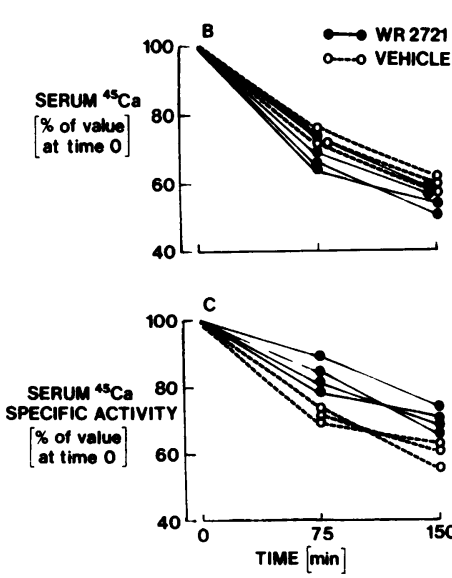

Serum calcium concentration was significantly lower in WR 2721-infused rats $(P$ $<0.001$ at both 75 and 150 min). (B) Serum ${ }^{45} \mathrm{Ca}$ activity given as a percentage of activity for the same rats at time $0(P>0.05$ at 75 and $150 \mathrm{~min}$ ). (C) Serum ${ }^{45} \mathrm{Ca}$ specific activity $\left({ }^{45} \mathrm{Ca}\right.$ activity/total calcium) is expressed as percentage of value at time $0(P<0.001$ at $75 \mathrm{~min}$ and $P<0.01$ at $150 \mathrm{~min}$ ). The serum ${ }^{45} \mathrm{Ca}$ specific activity for the WR 2721-infused rats at time 0 was $5.8 \pm 1.4 \times 10^{5} \mathrm{cpm} / \mathrm{mg}$ and $7.0 \pm 2.9 \times 10^{5} \mathrm{cpm} / \mathrm{mg}$ in vehicleinfused rats. calcium but only slightly increased the rate of disappearance of isotope $(93 \%$ of vehicle infused rats at $75 \mathrm{~min}$ and $92 \%$ at $150 \mathrm{~min}, P>0.05$ ). In contrast, the specific activity of ${ }^{45} \mathrm{Ca}$ in serum $\left({ }^{45} \mathrm{Ca}\right.$ radioactivity/total calcium) was significantly higher in WR 2721-infused rats at both time points (Fig. 4 $C$ ). (This occurs because the lower ${ }^{45} \mathrm{Ca}$ activity in the numerator is greatly outweighed by the change in the denominator, total serum calcium.) In another similar experiment (data not shown), ${ }^{45} \mathrm{Ca}$ specific activity was also significantly higher in WR 2721 than vehicle infused rats; in that experiment there was no difference in the rate of decline of ${ }^{45} \mathrm{Ca}$ activity. These data suggest that the predominant effect of WR 2721 is to block the release of calcium into serum. Although it is possible that WR 2721 also enhances the exit of ${ }^{45} \mathrm{Ca}$ from serum, this appears to account for only a small proportion of the change in serum calcium.

The effects of WR 2721 on radiocalcium kinetics were also examined in rats $17 \mathrm{~d}$ after the rats were injected with ${ }^{45} \mathrm{Ca}$. At this time, most of serum ${ }^{45} \mathrm{Ca}$ derives from release from prelabeled bone pools. WR 2721 significantly decreased serum concentrations of both total and isotopic calcium when compared with vehicle infused rats (Table I). However, there was no difference in the specific activity of ${ }^{45} \mathrm{Ca}$ in serum between the two groups. These results do not support any particular mechanism. They are consistent with the results of the prior kinetic experiment if WR 2721 reduced the release of ${ }^{45} \mathrm{Ca}$ from a pool with a specific activity in equilibrium with serum. This could also occur if WR 2721 enhanced the exit of calcium from serum.

Bone resorption by fetal rudiments in organ culture. Concentrations of WR 2721 up to $10^{-3} \mathrm{M}$ did not significantly reduce base-line release of ${ }^{45} \mathrm{Ca}$ from fetal rat long bones after $4 \mathrm{~d}$ of culture (Fig. 5). In control cultures, bone resorptive activity was stimulated by the addition of 200 and 1,000 $\mathrm{ng} / \mathrm{ml}$ PTH. In contrast, PTH-stimulated bone resorption was prevented by the simultaneous administration of $10^{-3} \mathrm{M}$ WR $2721(P<0.001) \cdot 10^{-4} \mathrm{M}$ WR 2721 caused variable inhibition of resorption stimulated by $1,000 \mathrm{ng} / \mathrm{ml}$ of PTH, but was as effective as $10^{-3}$ M WR 2721 in inhibiting resorption stimulated by $200 \mathrm{ng} / \mathrm{ml}$ PTH $(P<0.001$, data not shown). The inhibition by WR 2721 may be a nonspecific effect of the drug on bone resorbing cells; this can not be entirely excluded. The fact that WR 2721 does not affect ultrastructural appearance of cultured osteoclasts (see below) on electron microscopy is evidence against this mechanism.

Bone resorption by isolated avian osteoclasts. WR 2721, in a dose-dependent manner, inhibited bone resorption by isolated osteoclasts (Fig. 6). At day 4, variable inhibition of ${ }^{45} \mathrm{Ca}$ release was present at $10^{-5} \mathrm{M}$, reproducibly demonstrated at $10^{-4} \mathrm{M}$, and maximally evoked at $10^{-3} \mathrm{M}$ WR 2721 . In general, $10^{-3}$ M WR 2721 caused a $25 \%$ reduction of base-line ${ }^{45} \mathrm{Ca}$ release.

There was no morphologic evidence of drug toxicity to cell cultures treated with WR 2721 in concentrations up to 1 $\mathrm{mM}$. Osteoclasts appeared viable, continued to exclude Trypan Blue, and remained adherent to the culture surface. Unlike control cultures, osteoclasts exposed to WR 2721 exhibited little tendency to associate with bone particles. At the ultrastructural level, many of the osteoclasts in contact with bone did not contain well-developed ruffled borders, the cytoplasmic specializations that characterize osteoclastic bone resorbing activity (15). 
Table I. Effect of WR 2721 on Total Serum Calcium, Serum ${ }^{45}$ Ca Activity, and Serum ${ }^{45} \mathrm{Ca}$ Specific Activity When Given $17 \mathrm{D}$ After Rats Were Given ${ }^{45} \mathrm{Ca}$

\begin{tabular}{|c|c|c|c|c|}
\hline & \multirow[b]{2}{*}{ Type of infusion } & \multicolumn{3}{|c|}{ Time after WR 2721 infusion $(h)$} \\
\hline & & 0 & 1 & 2 \\
\hline \multirow[t]{2}{*}{ Serum calcium $(\mathrm{mg} / 100 \mathrm{ml})$} & Vehicle & $9.9 \pm 0.4$ & $9.8 \pm 0.1$ & $9.5 \pm 0.2$ \\
\hline & WR 2721 & $10.2 \pm 0.5$ & $7.7 \pm 0.3^{*} \ddagger$ & $7.9 \pm 0.3^{*} \ddagger$ \\
\hline \multirow[t]{2}{*}{${ }^{45} \mathrm{Ca}$ activity $(\mathrm{cpm} / \mathrm{ml})$} & Vehicle & $5,338 \pm 307$ & $5,758 \pm 502$ & $5,846 \pm 538$ \\
\hline & WR 2721 & $5,304 \pm 405$ & $4,313 \pm 153 \S^{\prime \prime}$ & $4,779 \pm 280 \pi$ \\
\hline${ }^{45} \mathrm{Ca}$ specific activity & Vehicle & $5.40 \pm 0.36$ & $5.91 \pm 0.52$ & $6.16 \pm 0.58$ \\
\hline$\left(\mathrm{cpm} / \mathrm{mg} \times 10^{-4}\right)$ & WR 2721 & $5.21 \pm 0.27$ & $5.61 \pm 0.23$ & $6.11 \pm 0.48$ \\
\hline
\end{tabular}

Vehicle or WR $2721(30 \mathrm{mg} / \mathrm{kg})$ was administered immediately after the first blood sample was obtained. Values shown are mean \pm SEM of values from four rats in each group. Paired $t$ statistic was used to compare results at 1 and $2 \mathrm{~h}$ to base-line values ( 0 time) within groups, and unpaired $t$ test to compare results between the two groups. ${ }^{*} P<0.01$ with respect to base-line values. $\ddagger P<0.001$ with respect to values in vehicle-infused rats. $\S P<0.05$ with respect to base-line values. " $P<0.01$ with respect to values in vehicle infused rats. $\pi P<0.10$ with respect to base-line values.

\section{Discussion}

On the basis of our previous in vivo and in vitro observations, we suggested that the hypocalcemic activity of WR 2721 was mediated in part by inhibiting PTH secretion (1). The present study indicates that the mechanism of WR 2721-induced hypocalcemia is more complex, since WR 2721 can produce hypocalcemia independent of its effect on parathyroid gland. Two experiments show that the hypocalcemic effect of WR

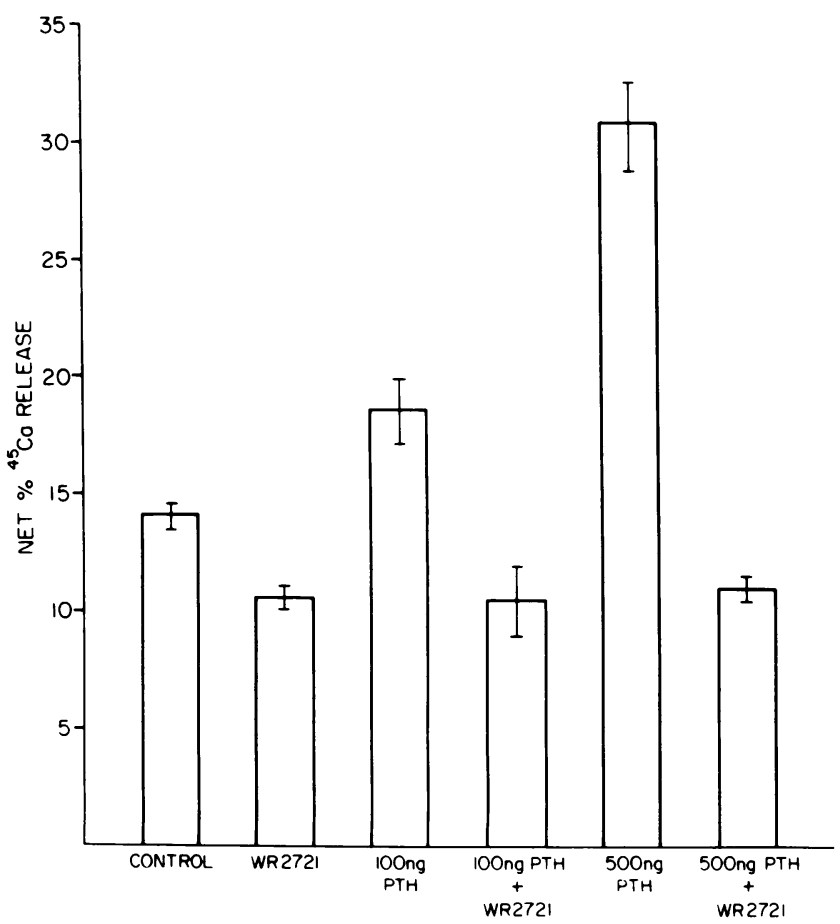

Figure 5. Effect of WR 2721 on bone resorption by osteoclasts in organ culture. Fetal rat long bone which had been labeled with ${ }^{45} \mathrm{Ca}$ in utero as described in Methods was incubated with or without $10^{-3}$ M WR 2721 and 100 or $500 \mathrm{ng}$ of added PTH $(200$ or $1,000 \mathrm{ng} / \mathrm{ml}$ respectively). Resorption is expressed as the percentage of calcium released from the bone. Each point is the mean \pm SEM of six cultures.
2721 is independent of its ability to reduce PTH levels. First, WR 2721 infusion into chronically PTX rats produced a fall in serum calcium concentration that was nearly identical to that observed in rats with intact parathyroid glands. Second, WR 2721 lowered the serum calcium concentration when administered to dogs receiving a constant PTH infusion. The hypercalcemic effect of the PTH infusion would have reduced endogenous secretion of PTH; thus, any direct effect of WR 2721 on the parathyroid glands would have little influence on the serum calcium.

WR 2721 could produce hypocalcemia by diminishing the entry of calcium into serum from pools such as bone or by enhancing its exit from serum into urine or tissues. Studies of the effect of WR 2721 on the kinetics of ${ }^{45} \mathrm{Ca}$ after acute infusion of the isotope were performed to distinguish between these possibilities. If WR 2721 accelerated the exit of calcium from serum, then total serum calcium and isotopic calcium would be reduced in the same proportion, and the rate of decline of serum ${ }^{45} \mathrm{Ca}$ specific activity would not differ from control animals. We found that when compared with vehicle infused rats, there was only a slightly greater fall in ${ }^{45} \mathrm{Ca}$ activity, whereas serum specific activity was significantly greater in the WR 2721-infused rats at both time points (Fig. 4). Therefore, the major effect of WR 2721 in lowering calcium appears to be an inhibition of calcium release into serum.

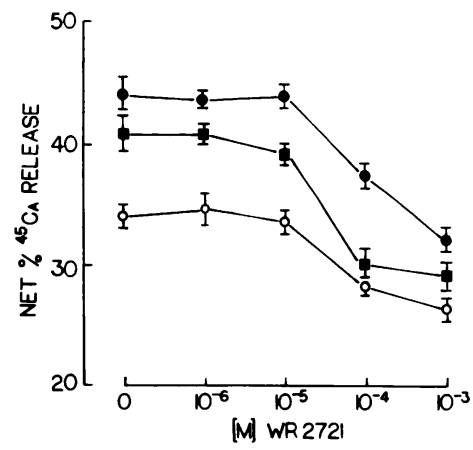

Figure 6. Effect of WR 2721 on bone resorption by isolated osteoclasts. Bone resorption is expressed as percentage of bone ${ }^{45} \mathrm{Ca}$ released into the medium. Cultures of osteoclasts were incubated for $4 \mathrm{~d}$ with the indicated concentrations of WR 2721. Percentage of ${ }^{45} \mathrm{Ca}$ release was determined on day 4 . Three separate representative experi-

ments are shown as separate curves. Each point represents the mean + SEM for 12 cultures. 
These results are similar to those obtained with other agents such as calcitonin $(16,17)$, mithramycin $(18)$, colchicine $(19)$, and protamine (20), which are believed to cause hypocalcemia by inhibiting bone resorption.

To further characterize the in vivo effects of WR 2721 on radiocalcium kinetics, bone pools of calcium were labeled with ${ }^{45} \mathrm{Ca}$ by injecting the isotope $17 \mathrm{~d}$ before WR 2721 administration. WR 2721 lowered both ${ }^{45} \mathrm{Ca}$ activity and total serum calcium in parallel so that there was no change in specific activity (Table I). These results are consistent with more than one hypocalcemic mechanism; specific activity would not change if WR 2721 enhanced calcium efflux from serum or if it blocked the release of ${ }^{45} \mathrm{Ca}$ into serum from pools (such as bone) that were in isotopic equilibrium with serum. These results are similar to those obtained in two similar studies with calcitonin $(17,21)$. Although the results of this particular experiment are inconclusive, the experiment examining radiocalcium kinetics after acute ${ }^{45} \mathrm{Ca}$ infusion suggests that WR 2721 inhibits the entry of calcium into the circulation. The finding that WR 2721 does not enhance urinary calcium excretion in dogs (see below) also lends further support to this hypothesis. These results do not necessarily indicate a direct drug-mediated inhibition of bone cell activity, since decreased bone resorption could have been caused by a reduction in circulating PTH concentration. However, the fact that WR 2721 lowered serum calcium in PTX rats and reduced serum calcium in dogs rendered hypercalcemic by constant PTH infusions suggests a direct effect of WR 2721 on bone resorption.

The results obtained by two different in vitro techniques to assess bone resorption indicate that WR 2721 affects bone cell activity directly. WR 2721 , in a dose related fashion, partially inhibited the bone resorptive activity of isolated osteoclasts and blocked the response of osteoclasts in organ culture to PTH. Although results obtained from the in vitro studies complement the in viyo findings, there are important differences. The acute onset (2-3 h) of transient $(<24 \mathrm{~h}$ in dogs and rats) hypocalcemia produced in vivo contrasts with the slower onset (days) of suppressed ${ }^{45} \mathrm{Ca}$ release in vitro. These differences in the time course may relate to differences in experimental systems. In contrast to in vivo responses, the in vitro bone resorption assays are not sufficiently sensitive to detect significant hour to hour fluctuations in calcium release. Instead, measurable changes in calcium are made possible by integrating the multiple small changes in mineral release that occur over a longer period of observation. The difference in time course may also reflect differences in rates of in vivo drug metabolism. Another difference between the in vitro and in vivo results is that only PTH-stimulated ${ }^{45} \mathrm{Ca}$ release and not base-line release was inhibited by WR 2721 in fetal rudiments, whereas hypocalcemia (presumably due to inhibition of bone resorption) occurred in PTX rats. This can be explained by the conditions of the rudiment bone assay where base-line (unstimulated) resorption is very low, and consequently inhibition of this activity is often not detectable.

No evidence of toxic effects was observed in the cultured cells. By electron microscopy, osteoclasts were free of degenerative changes. There were qualitative changes; ruffled border formation and clear zone development with cell-matrix attachment were reduced, which suggested that osteoclasts were inactive (15). Similar morphologic changes are seen when osteoclasts are inhibited by calcitonin (22).
The importance of the parathyroid-inhibitory effect of WR 2721 in producing hypocalcemia is unclear. The nearly identical acute fall in serum calcium levels in the PTX and parathyroidintact rats suggests that the parathyroid-inhibitory effect of WR 2721 plays no role in its acute hypocalcemic effect. There are other interpretations. The nearly identical decline in serum calcium in the two groups could also occur if the parathyroidinhibitory effect contributed to the hypocalcemia in the rats with intact glands. If WR 2721 had no effect on these glands, a compensatory response could, to some degree, blunt the fall in serum calcium. Furthermore, the experimental design probably minimized the contribution of the parathyroid glands, since on a low phosphate diet, the enhanced release of calcium from bone would inhibit PTH secretion and minimize its role in maintaining the serum calcium. Another interpretation of the role of the parathyroid-inhibitory effect is that the consequences of this effect occur later. In these studies we concentrated on the changes in serum calcium in the first $2-3 \mathrm{~h}$ after administration of WR 2721. As noted above, the effect of acute hypoparathyroidism may require more time to influence the serum calcium. Further studies are required to distinguish between these various possibilities.

Several agents have been described which produce hypocalcemia as a result of inhibiting calcium release from bone. These include calcitonin $(16,17)$, mithramycin $(18)$, protamine (20), diphosphonates $(23,24)$, colchicine (19), and thiophene2-carboxylic acid (25). None of these agents are known to inhibit PTH secretion. Although the in vivo and in vitro pattern of WR 2721-induced hypocalcemia resembles superficially that produced by calcitonin, it is unlikely that the calcium lowering effect of WR 2721 is mediated by WR 2721induced release of calcitonin. We have measured immunoreactive calcitonin levels $15 \mathrm{~min}$ and $2 \mathrm{~h}$ after the infusion of WR 2721 into patients. No consistent change in calcitonin levels was found in these individuals despite a $20 \%$ reduction in serum calcium level (Heath, H., unpublished observations). Furthermore, in vitro bone resorption assays suggest that WR 2721 directly inhibits bone resorption by osteoclasts and blocks the ability of osteoclasts to respond to hormonal stimuli.

The concurrence of an effect on both the parathyroid gland and bone by a single agent is, to our knowledge, unique. There are no known endogenous circulating factors that inhibit the action of both organs. Dephosphorylated WR 2721 in cells with its free sulfhydryl group could alter the redox state of cellular constituents (such as pyridine nucleotides and glutathione), which in turn could affect a number of cell processes including calcium translocation. Moreover, a wide variety of cellular proteins contain critical sulfhydryl groups with which this compound could form mixed disulfides. There is also the possibility that other regions of the molecule are active in producing hypocalcemia. In summary, more information is needed on the cellular effects of WR 2721 in parathyroid and bone as well as other tissues before one could propose a cellular mechanism of action.

In conclusion, these studies show that WR 2721 causes hypocalcemia by inhibiting calcium release from bone. Our studies in vivo with parathyroidectomized rat and PTHinfused dogs suggest that a significant component of the acute effect of WR 2721 is independent of its effect on the parathyroid gland. Our studies using two in vitro models of bone resorption indicate that WR 2721 directly affects this process. The dual 
mechanism of action suggests that WR 2721 or its analogues are potentially useful in hypercalcemia due to excess PTH secretion and/or bone resorption. Furthermore, the unique mechanism of action of WR 2721 may provide new insight into the regulatory mechanisms in these tissues.

\section{Acknowledgments}

We gratefully acknowledge the technical assistance of Dorothy Senesky, Sandra Marcus, Bobbie Ladenson, and Karen York, and the secretarial assistance of Judith Simms. We also thank Dr. Gerald D. Aurbach and Dr. Charles Ramberg for helpful discussions and Dr. David Kowalczyk for generously allowing the use of his atomic absorption spectrophotometer.

This work was supported in part by U. S. Public Health Service grants RR 00040, AM 31826, AM 32325, AM 32707, AM 09976, and T32-AM 07006

\section{References}

1. Glover, D., L. Riley, K. Carmichael, B. Spar, J. Glick, Z. Agus, E. Statopolsky, M. Attie, and S. Goldfarb. 1983. Hypocalcemia and inhibition of parathyroid hormone secretion following administration of WR 2721 (a radio- and chemoprotective agent). N. Engl. J. Med. 309:1137-1141.

2. Yuhas, J. M., J. M. Spellman, and F. Culo. 1980. The role of WR 2721 in radiotherapy and/or chemotherapy. Cancer Clin. Trials. 3:211-216.

3. Yuhas, J. M., and J. B. Storer. 1969. Differential chemoprotection of normal and malignant tissues. J. Nat. Cancer Inst. 42:331-335.

4. Phillips, T. L., L. Kane, and J. F. Utley. 1973. Radioprotection of tumor and normal tissues by thiophosphate compounds. Cancer. 32:528-535.

5. Goldfarb, S., P. Bosanac, M. Goldberg, and Z. S. Agus. 1978. Effects of calcium on renal tubular phosphate reabsorption. Am. J. Physiol. 234:F22-29.

6. Hruska, K. A., R. Kopelman, W. E. Rutherford, S. Klahr, and E. Slatopolsky. 1975. Metabolism of immunoreactive parathyroid hormone. The role of the kidney and the effects of chronic renal disease. J. Clin. Invest. 56:39-45.

7. Raisz, L. E. 1965. Bone resorption in tissue culture. Factors influencing the response to parathyroid hormone. J. Clin. Invest. 44: 103-116.

8. Osdoby, P., M. K. Martini, and A. I. Caplan. 1982. Isolated osteoclasts and their presumed progenitor cells, the monocyte, in culture. J. Exp. Zool. 224:331-344.

9. Fallon, M. D. 1983. Osteoblasts mediate osteoclastic bone resorption in cell culture. Calcif. Tissue Int. 35:640. (Abstr.)

10. Teitelbaum, S. L., C. C. Stewart, and A. J. Kahn. 1979. Rodent peritoneal macrophages as bone resorbing cells. Calcif. Tissue Int. 27: 255-261.

11. Milas, L., N. Hunter, I. Hisao, E. L. Travis, and L. J. Peters. 1983. Factors influencing radioprotection of tumors by WR 2721. In Radioprotectors and Anticarcinogens. O. F. Nygaard and M. G. Simic, editors. Academic Press, Inc., New York. 695-718.

12. Purdie, J. W., E. R. Inhaber, H. Schneider, and J. L. Labelle. 1983. Interaction of cultured mammalian cells with WR 2721 and its thiol, WR 1065; implications for mechanisms of radioprotection. Int. J. Radiat. Biol. 43:517-527.

13. Tabachnik, N. F., C. M. Peterson, and A. Cerami. 1980. Studies on the reduction of sputum viscosity in cystic fibrosis using an orally absorbed protected thiol. J. Pharmacol. Exp. Ther. 214:246249.

14. Rosenbaum, R. W., K. A. Hruska, A. Korkor, C. Anderson, and E. Slatopolsky. 1981. Decreased phosphate reabsorption after renal transplantation: evidence for a mechanism independent of calcium and parathyroid hormone. Kidney Int. 19:568-578.

15. Gothlin, G., and J. L. E. Ericsson. 1976. The osteoclast. Clin. Orthop. Relat. Res. 120:201-231.

16. O'Riordan, J. L. H., and G. D. Aurbach. 1968. Mode of action of calcitonin. Endocrinology. 82:377-383.

17. Talmage, R. V., J. J. B. Anderson, and C. W. Cooper. 1972. The influence of calcitonins on the disappearance of radiocalcium and radiophosphorus from plasma. Endocrinology. 90:1185-1191.

18. Kiang, D. T., M. K. Loken, and B. J. Kennedy. 1979. Mechanism of the hypocalcemic effect of mithramycin. J. Clin. Endocrinol. Metab. 48:341-344.

19. Heath, D. A., J. S. Palmer, and G. D. Aurbach. 1972. The hypocalcemic action of colchicine. Endocrinology. 90:1589-1593.

20. Johnston, C. C. J., E. L. Grinnan, H. C. Wilson, and G. B. Boder. 1970. Protamine-induced hypocalcemia. Endocrinology. 87: 1211-1217.

21. Johnston, C. C. J., and W. P. Deiss. 1966. An inhibitory effect of thyrocalcitonin on calcium release in vivo and on bone metabolism in vitro. Endocrinology. 78:1139-1143.

22. Chambers, T. J., and C. J. Magnus. 1982. Calcitonin alters behavior of isolated osteoclasts. J. Pathol. 136:27-39.

23. Jacobs, T. P., E. S. Siris, J. P. Bilezekian, D. C. Baquiran, E. Shane, and R. E. Canfield. 1981. Hypercalcemia of malignancy: treatment with intravenous dichloromethylene diphosphonate. Ann. Int. Med. 94:321-326.

24. Fleisch, H., R. G. G. Russell, and M. D. Francis. 1969. Diphosphonates inhibit hydroxyapatite dissolution in vitro and bone resorption in tissue culture and in vivo. Science (Wash. DC). 165: 1262-1264.

25. Lloyd, W., V. S. Fang, H. Wells, and A. H. Tashjian, Jr. 1969. 2-Thiophenecarboxylic acid: a hypoglycemic, antilipolytic agent with hypocalcemic and hypophosphatemic effects in rats. Endocrinology. 85:763-768. 